\title{
The Effectiveness of Thermal Insulated Concrete Blocks in Oman
}

\author{
Almaawali S* and Ahmad A \\ University of Nizwa, Oman
}

*Corresponding author: Almaawali S, Civil and Environmental Engineering Department, College of Engineering and Architecture, University of Nizwa, Oman.

\begin{abstract}
The high consumption of energy became a danger constitutes to the environment and increases the monthly consumer costs. This leads to the think for some alternative materials that can helps us to avoid these problems. The objective of this study is to measure the effectiveness of thermal insulated concrete blocks in Oman. Study of this kind of blocks have many values and in order to evaluate the results compared with nonthermal insulated concrete blocks. This report is summarized, study the energy consumption, environment-impact and measure the consumer satisfaction for the usage of thermal insulated concrete blocks. The results indicated that the thermal insulated blocks) has a good strength and it shows high efficiency of insulation more than 50 percent compared to (normal blocks). In addition, it helps to save energy consumption and protect the environment. In conclusion it was proved that the (thermal insulated blocks) is the most appropriate choice for the building in Oman.
\end{abstract}

\section{Problem Statement}

Oman has a dry hot climate, and most of the year temperatures are elevated significantly, it is usually during the summer day beyond $45^{\circ}$, while during the winter months is not less than $15^{\circ} \mathrm{C}$. This highlights the need for solutions and innovations to cope with this climate and to reduce heat loss into the structures. Thermal insulation is defined as the reduction of heat transfer in whole or in part from the place of operation to another and it is by using some of the materials are characterized as having characteristics such as poor heat conduction and reflection characteristic so as to contribute to the reduction of heat loss. The thermal insulation many benefits, including reducing the consumption of electricity and the piece in homes cooling and heating. One method to increase the thermal insulation in building is the usage of thermal insulted concrete block. This type of blocks is made by inserting a layer of Polystyrene in the core of block.

\section{Methodology}

The following steps were followed to obtain results of this study:

1. Conducting a site visit to thermal insulated blocks factory in the Sultanate of Oman, in order to take some interviews and to collect the information that will assist in complete this study.
2. Conduct a laboratory test to check the compressive strength and the thermal insulation ratio for these blocks.

3. Study (the energy consumption and environment-impact) in using of thermal insulated blocks in construction.

4. Comparing between the thermal insulated blocks and the normal blocks.

5. Distribute a questionnaire to get information for consumer satisfaction.

\section{Result and Discussion}

The compressive strength test is done for both thermal insulated blocks and Normal blocks. That, to apply for the both types. The tests were showed that the average compressive strength of the normal blocks was $10.388 \mathrm{MPa}$ ) and $9.162 \mathrm{MPa}$ for the Thermal insulated block. Through these results we can see that the difference in strength between the two samples is not large. And therefore, the thermal insulated block has sufficient strength. The thermal conductivity test is done using (Heat Insulation) device. The results showed a significant change in temperature for the normal block, while it he was a small change in the thermal insulated block. The thermal conductivity ratio for normal block is (34\%), and the 
ratio for the thermal conductivity for thermal insulated blocks is $(5.9 \%)$. Generally, from this test, we can say that the thermal insulated blocks have a very strong insulation ratio compared to the normal blocks. Another site inspection test was done for two residential houses; one was built with (Thermal insulated blocks) and the other built with (Normal blocks). Both of them are contain rooms with same size, so as to obtain accurate results. Where the idea of this test was to operate the air conditioner (AC) for a full hour and then switch it off and wait for another an hour. Then we measured the Heat loss for both rooms using (Thermometer). The results showed that the rate of heat loss in (room build with Normal blocks) is very large, while the thermal insulated ratio obtained in (room build with Thermal insulated blocks) is very good.

\section{Conclusion}

From the lab tests and survey conducted with some consumers it was proved in this study that the usage of thermal insulated blocks is very effective in hot climates such as Oman's climate. The only disadvantage raised by some survey participants was that the thermal insulted blocks is a bit higher cost than the normal cost which can be overcome by the decrease in the electricity consumption.

\section{Acknowledgement}

None.

\section{Conflict of Interest}

No conflict of interest. 